\title{
A tradução na área de química orgânica: da adaptação à tradução literal
}

\author{
Paula Tavares Pinto \\ Universidade Estadual Paulista "Júlio de Mesquita Filho" (UNESP), \\ São José do Rio Preto, São Paulo, Brasil \\ paula.pinto@unesp.br \\ http://orcid.org/0000-0001-9783-2724 \\ Marcelo de Freitas Lima \\ Universidade Estadual Paulista "Júlio de Mesquita Filho" (UNESP), \\ São José do Rio Preto, São Paulo, Brasil \\ marcelo.flima@unesp.br \\ http://orcid.org/0000-0003-3191-2494
}

\section{DOI: http://dx.doi.org/10.21165/el.v47i2.2050}

\section{Resumo}

Neste trabalho, propomos uma discussão sobre a problemática da tradução de termos em inglês da Química de Pesticidas, subárea da Química Orgânica, para o português do Brasil. O objetivo principal é o de apresentar um glossário bilíngue (português $\Leftrightarrow$ inglês) com termos harmonizados, buscando preencher uma lacuna existente e oferecer uma fonte de consulta confiável para os pesquisadores da área. Para tal, utilizamos como base teórica os estudos da tradução baseados em corpus, a Linguística de Corpus e a Terminologia. Para a composição do corpus, de onde serão extraídas as informações e os termos, são utilizados artigos e resumos de revistas acadêmicas que tratam de química de pesticidas em português brasileiro e em inglês.

Palavras-chave: tradução; Terminologia; Linguística de Corpus; química orgânica.

\section{Translation in the area of Organic Chemistry: from adaptation to literal translation}

\begin{abstract}
In this paper, we discuss translation problems in Organic Chemistry, subarea of chemistry of pesticides, from English to Brazilian Portuguese. The main objective is to present a bilingual glossary (Portuguese $\Leftrightarrow$ English) with the methodology of Corpus Linguistics and Terminology to propose harmonization in the use of terms in both languages. For the corpus compilation, we used articles and abstracts of academic journals dealing with Pesticide Chemistry in English and in Brazilian Portuguese.
\end{abstract}

Keywords: translation; terminology; corpus linguistics; organic chemistry.

\section{Introdução}

Nos anos de 2016 e 2017, o Brasil se consagrou como o segundo maior exportador de soja mundial, o que o tornou, por consequência, o maior importador de pesticidas voltados para este fim. Dentre os produtos químicos importados está o glifosato, herbicida que é líder internacional em vendas. Dado esse contexto, pesquisadores da área da Química buscam estudar e criar um conjunto de metodologias ambientalmente sustentáveis para a degradação de pesticidas que sejam comercializados 
clandestinamente ou que façam parte de estoques com validade expirada, uma vez que são altamente prejudiciais à saúde da população em geral. Com base na compreensão do mecanismo de degradação, é possível inferir sobre formas de sintetizar novas moléculas e assim propor novas substâncias ou materiais voltados à ação biosseletiva no controle de pragas da atividade agrária.

Muito embora a necessidade destes estudos seja reconhecida internacionalmente, quando se trata de publicações que divulguem as pesquisas brasileiras, ou da escrita de dissertações de mestrado e teses de doutorado, o vocabulário pertencente a essa área é extremamente baseado em terminologias históricas de uma linguagem complexa, por exemplo, o pesticida organoclorado Aldrin que teve seu nome inspirado no cientista alemão Kurt Alder que foi um dos criadores da rota de síntese do agrotóxico. Não existe, ainda, um consenso sobre o uso de termos padronizados na língua portuguesa e, por este motivo, os autores de trabalhos científicos acabam empregando termos em língua inglesa ou empregando o decalque dos termos na língua portuguesa.

A instituição IUPAC - International Union of Pure and Applied Chemistry - já teve como objetivo tornar a comunicação dessa área do conhecimento mais transparente entre as nações. No entanto, a nomenclatura em Química ainda é regional, ao contrário de sua simbologia, que é universal. Quando traduções são propostas, elas são precariamente normatizadas. Para Azenha Jr. (1999), embora as condições da comunicação técnica sejam, até certo ponto, mais controladas, a terminologia utilizada nessa forma de tradução é dinâmica e admite uma "margem de subjetividade". Em seu trabalho, o autor enfatiza a ocorrência de aspectos culturais na tradução de textos técnicos, porquanto fazem parte do relacionamento entre linguagem, cultura, texto e tradução.

Pesquisadores da Química relatam que ainda não existe uma linearidade na escolha dos equivalentes tradutórios para cada termo e que, muitas vezes, utiliza-se o decalque, entendido aqui como uma adaptação do termo na língua de chegada, ou até mesmo o empréstimo do termo em inglês mesmo após a proposta de um equivalente na língua de chegada ter sido apresentada, a fim de tornar claro o processo em questão. Como exemplos, pode-se citar o caso dos termos vazamento (português) e casting (inglês) que tratam do ato de processar um material originalmente líquido por meio de um sistema de moldagem (ANDRADE et al., 2001). Outro exemplo seria o uso do termo cromatografia líquida de alta velocidade, ou também "de alto desempenho", ou "de alta resolução", ou "alta eficiência", ou ainda de "alta pressão", todas as versões encontradas comumente em artigos da área de química para designar o termo único em inglês high-performance liquid cromatography (HPLC) (COLLINS; BRAGA; BONATO, 2006). Este problema ocorre devido ao fato de muitos termos da área, traduzidos para o português, não expressarem de forma concisa o significado que o termo em inglês possui. Além disso, por muitas vezes, ocorre de a tradução de um termo não ser de conhecimento ou aceitação de todos os usuários, uma vez que, quando essas traduções são propostas, não são devidamente normatizadas tendo em vista a diversidade de pesticidas que cresce exponencialmente ano após ano e o número de publicações e normas técnicas dedicadas tanto aos casos "clássicos" quanto aos "novos". Por este motivo, as traduções acabam limitadas à comunidade que as propôs.

Com vistas a auxiliar os pesquisadores e acadêmicos da área da Química Orgânica, mais especificamente, da Química de Pesticidas, um projeto interdisciplinar 
foi criado e as discussões sobre as traduções problemáticas do domínio já foram iniciadas. Esse artigo visa divulgar o estado da pesquisa até o momento, algumas discussões bastante pertinentes, e alguns resultados parciais. Como bases teóricas para o trabalho, serão utilizados os Estudos da Tradução (AZENHA Jr., 1999), a contribuição da Linguística de Corpus (BERBER SARDINHA, 2004) e da Terminologia (BARROS, 2004; KRIEGER; FINATTO, 2004). Essa abordagem interdisciplinar forneceu as bases teórico-metodológicas para a composição de um corpus composto por trabalhos científicos que tratam das substâncias químicas classificadas como agrotóxicos nas línguas portuguesa e inglesa. A partir desse corpus, a terminologia específica da área e seus contextos de uso são extraídos com vistas à elaboração de um glossário bilíngue. Este vocabulário especializado será de grande importância e impacto científico, uma vez que será empregado em relatórios de pesquisa e outros textos acadêmicos nas duas línguas pelos pesquisadores juniores e seniores do grupo de pesquisa do Departamento de Química e Ciências Ambientais, podendo ser, posteriormente, divulgado para utilização de outros profissionais e estudiosos ligados à área. Neste processo, acreditamos que os alunos de Química aprimorarão sua escrita acadêmica em língua inglesa com os termos observados e harmonizados após nosso trabalho.

\section{Fundamentação teórica}

Maria da Graça Krieger e Maria José Bocorny Finatto (2004) destacam o interesse do mundo globalizado pela informação referente à produção científica e tecnológica. Esse interesse faz com que aumente a demanda por traduções técnicas e, por consequência, que o tradutor se depare com diversos termos de diferentes áreas. As autoras destacam que o uso de termos não se dá com a intenção de dificultar o acesso da informação a não iniciantes das áreas. Eles são uma forma de expressão própria de uma determinada área, carregando conceitos próprios dela, mas seu uso é favorável à eficácia comunicativa, por conferirem univocidade ao texto. Desta forma, interessa ao tradutor um manejo terminológico competente, para que ele possa resgatar todas essas características presentes no texto.

\section{Tradução e Terminologia}

Pesquisadores dos Estudos da Tradução e da Terminologia reconhecem que os dois campos, embora se dediquem a objetos de pesquisa distintos, podem complementar-se, principalmente em se tratando da tradução técnica ou especializada. Tal pensamento é compartilhado por Krieger e Finatto (2004, p. 65) ao afirmarem que "a Tradução e a Terminologia mantêm uma série de confluências, mas suas identidades e propósitos específicos não se superpõem". A esse respeito, Aubert (1996, p. 13) esclarece que:

Os estudos terminológicos e os estudos da tradução constituem disciplinas autônomas entre si. A terminologia, enquanto campo de investigação, entretém relações estreitas com a lexicologia, a lexicografia e a semântica, embora não se confunda com estas nem constitua simplesmente uma sub-área das mesmas, e seu estatuto de área de aplicação da linguística e/ou da sociolinguística parece inquestionável. A tradutologia, por sua vez, tem por objetivo a análise de um fenômeno complexo, ao mesmo tempo linguístico, sociocultural, histórico, estético, político e individual. 
Cientes das diferenças entre as duas áreas, mas também das produtivas interrelações que se estabelecem, apoiamo-nos, em parte, na Terminologia, para o levantamento e estudo dos termos da Química de Pesticidas que realizamos. Nesta pesquisa, são observados os termos especializados entendidos como a "designação, por meio de uma unidade linguística, de um conceito definido em uma língua de especialidade" (ISO ${ }^{1}$ 1087, 1990, p. 5 apud BARROS, 2004, p. 40). Para nos referirmos às listas de termos a serem levantados, adotamos o termo glossário em nosso trabalho, conforme a definição de Barros (2004, p. 144):

Glossário (termo tolerado: dicionário bilíngue, dicionário multilíngue): pode situar-se tanto no nível do sistema como no da(s) norma(s). Sua principal característica é não apresentar definições, mas tão somente uma lista de unidades lexicais ou terminológicas acompanhadas de seus equivalentes em outras línguas.

Uma decisão tomada em grupo com os colegas desse projeto interdisciplinar é que devem ser acrescentados aos termos do glossário resultante deste estudo o contexto em que eles aparecem. Esse contexto pode ser definitório, explicativo, associativo ou enciclopédico (BARROS, 2004), a depender do que o corpus oferece. Sabemos que os tipos de contextos mais interessantes são os definitórios e os explicativos, pois assim o pesquisador terá mais descritores que permitam atestar sua equivalência nas línguas envolvidas. Entretanto, sempre que existente, serão registrados os contextos para a verificação do termo "in vivo", o que contribui grandemente para seu entendimento, principalmente do ponto de vista pragmático.

Para levantar os termos, observamos os usos mais frequentes da subárea, nas duas línguas, e tentamos estabelecer a relação de equivalência (ou correspondência) entre os termos na língua de partida em relação ao uso dos equivalentes ou correspondentes na língua de chegada. A esse respeito, Robert Dubuc (1985) realiza um estudo sobre essa correspondência de termos equivalentes e sugere que o equivalente, no caso do termo na língua de chegada, recobriria traços conceptuais e pragmáticos do termo da língua de partida; já o correspondente seria o termo na língua de chegada que possui traços conceptuais e pragmáticos idênticos e outros diferentes do termo da língua de partida. Ou seja, a verificação dessa equivalência deverá ser feita com auxílio dos especialistas da área, nesse caso, os pesquisadores do Departamento de Química e Ciências Ambientais.

Para o estudo das características de glossários especializados, baseamo-nos, além de Barros (2004), nas publicações de Krieger e Finatto (2004). As autoras apresentam um guia de como se elaborar um glossário especializado. Antes de se iniciar a elaboração do glossário, deve-se fazer um planejamento levando em consideração a estrutura que terá a obra, o modo de armazenamento das informações coletadas, etc. O segundo passo seria o reconhecimento dos termos. Para tanto, o tradutor precisa estar atento para perceber que, muitas vezes, itens lexicais que são comumente utilizados na linguagem comum/geral podem estar sendo empregados no texto especializado com um significado específico. O terceiro passo seria, então, realizar uma preparação geral do trabalho, levando em consideração os seguintes itens:

\footnotetext{
${ }^{1}$ ISO = International Standards Organization.
} 
a) o produto deve atender às necessidades de um público-alvo, e de preferência preencher uma lacuna de informação;

b) todos os dados registrados ou utilizados para a futura geração do produto devem ser plenamente confiáveis;

c) a utilização e a ordem dos dados registrados, os signos para a sua representação, bem como os símbolos utilizados para identificar dados coletados devem ser convencionais e sistemáticos, preferencialmente, oriundos de padrões de normas nacionais ou internacionais;

d) a ordenação dos dados de informação sobre o termo no interior de uma ficha de registro ou uma base de dados e também o modo de organização das entradas no dicionário devem ser adaptadas aos objetivos do trabalho e ao uso que será feito das informações (KRIEGER; FINATTO, 2004, p. 128).

Finalmente, o quarto passo seria a listagem dos termos, já na forma de glossário. Atualmente, o projeto que se iniciou há quatro anos está na fase de levantamento de termos e busca de seus equivalentes em português. Alguns problemas já se apresentaram e serão tratados em seção posterior deste artigo.

\section{A Linguística de Corpus para o levantamento terminológico}

A Linguística de Corpus tem tido uma função primordial para a tradução de textos especializados, principalmente no caso de se observar os termos realmente empregados pela comunidade científica da língua de chegada. Em virtude de trabalhar com dados reais utilizando corpora eletrônicos, a Linguística de Corpus tem fornecido uma abordagem que possibilita a observação de redes semânticas e campos lexicais, o que facilita ao analista trabalhar com grandes quantidades de dados.

Segundo Beber Sardinha, a definição que engloba as características principais de um corpus computadorizado é a de Sanchez (1995, p. 8-9 apud BERBER SARDINHA, 2000, p. 338):

Um conjunto de dados linguísticos (pertencentes ao uso oral ou escrito da língua, ou a ambos), sistematizados segundo determinados critérios, suficientemente extensos em amplitude e profundidade, de maneira que sejam representativos da totalidade do uso linguístico ou de algum de seus âmbitos, dispostos de tal modo que possam ser processados por computador, com a finalidade de propiciar resultados vários e úteis para a descrição e análise.

Essa definição, para o autor, reúne os mais importantes pontos a serem seguidos na construção de um corpus, a saber:

(a) A origem: os dados devem ser autênticos.

(b) O propósito: o corpus deve ter a finalidade de ser um objeto de estudo linguístico.

(c) A composição: o conteúdo do corpus deve ser criteriosamente escolhido.

(d) A formação: os dados do corpus devem ser legíveis por computador. 
(e) A representatividade: o corpus deve ser representativo de uma língua ou variedade.

(f) A extensão: o corpus deve ser vasto para ser representativo. (BERBER SARDINHA, 2004, p. 18-19).

A representatividade e a extensão do corpus estão diretamente ligadas às necessidades do pesquisador. A extensão do corpus comporta três dimensões: o número de palavras (quanto maior o número de palavras maior será a possibilidade de o corpus conter palavras de baixa frequência); o número de textos do corpus específico (o número maior de textos garante que o tipo textual, gênero ou registro, esteja mais adequadamente representado); número de gêneros, registros ou tipos textuais (no caso de corpora variados, criados para representar uma língua como um todo). No estudo proposto, embora os subcorpora compilados se enquadrem na especificação de tamanho pequeno-médio, como veremos abaixo, consideramos os corpora a serem utilizados como representativos do gênero analisado, ou seja, artigos publicados em revistas bilíngues da área de Química. São representativos também por apresentar textos que seguem o mesmo padrão linguístico exigido por revistas conceituadas nesta área.

Diferentemente, a questão do tamanho do corpus é de natureza subjetiva, ou seja, "os usuários de um corpus atribuem a ele a função de serem representativos de uma certa variedade"; também cabe a esses usuários "serem cuidadosos em relação à generalização dos seus achados para uma população inteira (um gênero ou a língua inteira, por exemplo)" (BEBER SARDINHA, 2000, p. 345).

Assim, a classificação de um corpus, com relação ao número de palavras, é a que segue (BERBER SARDINHA, 2004, p. 26):

\begin{tabular}{|l|l|}
\hline Tamanho em palavras & Classificação \\
\hline Menos de 80 mil & Pequeno \\
\hline 80 a 250 mil & Pequeno-médio \\
\hline 250 mil a 1 milhão & Médio \\
\hline 1 milhão a 10 milhões & Médio-grande \\
\hline 10 milhões ou mais & Grande \\
\hline
\end{tabular}

Acreditamos que após a seleção de textos e organização dos corpora de estudo, teremos uma coletânea de tamanho médio, que poderá ser atualizada e expandida com o passar dos anos em que o estudo estiver sendo realizado.

Utilizaremos dois tipos de corpora, o comparável, ou seja, composto por textos de mesmo gênero e tipologia textual, e corpus paralelo, compostos por textos originais e respectivas traduções.

\section{Sobre as regras e a nomenclatura de termos}

A discussão sobre a tradução do texto especializado e da busca de equivalentes para os termos na área de Química de Agrotóxicos para o português brasileiro foi previamente sugerida por Abakerli et al. (2003). A Química de Agrotóxicos ou Química de Pesticidas é um sub-ramo da Química que se dedica ao estudo de substâncias com 
propriedades de inibir a proliferação de determinados organismos prejudiciais à prática da agricultura. No fluxograma da Figura 1, podemos ver onde esse sub-ramo da Química se situa em relação às quatro áreas básicas da Química, ou seja, vemos uma árvore do domínio (BARROS, 2004):

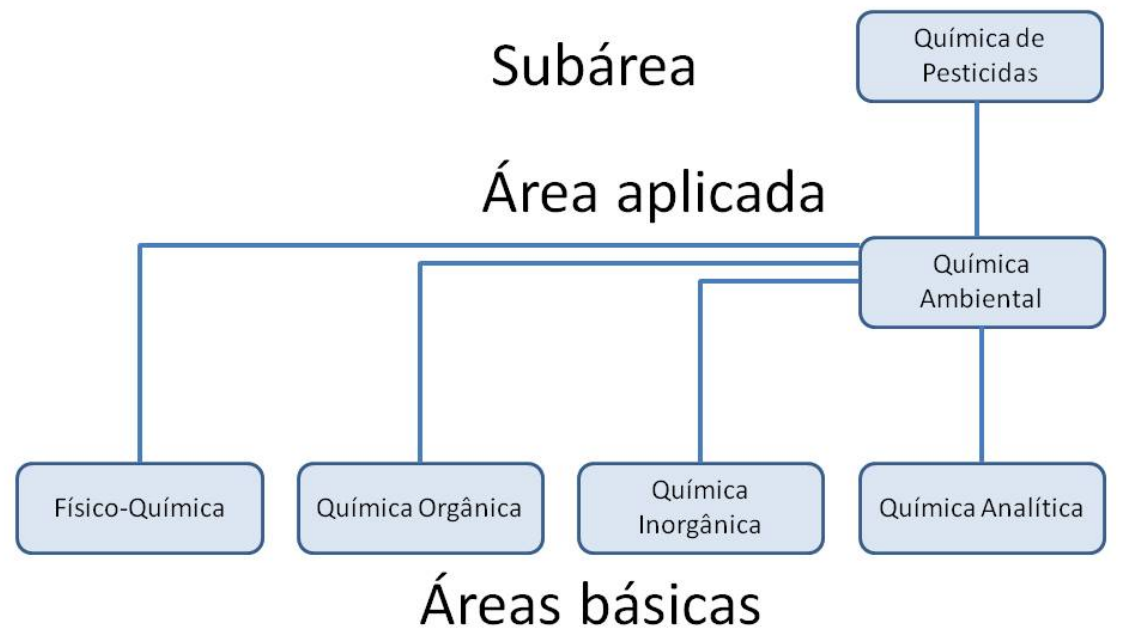

Figura 1. Fluxograma esquemático mostrando a inserção da subárea da Química de Pesticidas no universo de estudo das quatro áreas principais da Química

A Figura 1 sugere que a Química de Pesticidas é um domínio multidisciplinar, envolvendo conhecimento de todas as áreas básicas da Química.

Profissionais diretamente envolvidos com o tema evidenciam a importância dessa discussão para registro adequado dos termos, mais especificamente dos nomes usuais, ou também chamados de não sistemáticos (aqueles que, embora não ambíguos, não seguem a normatização da IUPAC), de agrotóxicos, neste caso. É interessante notar que Abakerli et al. (2003) e colaboradores pertencem a instituições como é a Empresa Brasileira de Pesquisa Agropecuária (EMBRAPA), a Agência Nacional de Vigilância Sanitária (ANVISA), o Ministério da Agricultura Pecuária e Abastecimento, dentre outros, mas eles não são tradutores ou terminólogos, os quais poderiam contribuir com os estudos, fornecendo inclusive diretrizes para a elaboração de obras terminológicas e/ou terminográficas.

Destacamos que a ISO 257 dita que seria ideal que a nomenclatura traduzida fornecesse nomes curtos, únicos e não ambíguos, de fácil pronúncia e grafia, que "facilitasse a comunicação e sua utilização conveniente nas esferas científica, comercial e governamental" (ISSO 257, p. 30). Explica-se ainda que, pelo fato de tais nomes não serem protegidos por patentes, não é permitido que se tornem marca registrada de produto idêntico ou semelhante. Acrescentam que, no Brasil, alguns produtos comerciais receberam o mesmo nome do ingrediente ativo, o que deveria ser evitado.

A padronização internacional dos nomes comuns dos agrotóxicos é efetuada pelo Comitê Técnico 81 (CT 81) da ISO, que procura garantir que haja consistência entre o nome atribuído e a representatividade da estrutura química da substância, sem que exista muita proximidade com o nome puramente químico (ou sistemático), aquele que é atribuído pela IUPAC. A facilidade de pronúncia do nome também é levada em 
conta. É de responsabilidade do mesmo Comitê que não haja coincidência com marcas de produtos comerciais existentes ou que conflitem com os nomes dos produtos farmacêuticos, possibilitando que o nome aprovado possa ser amplamente empregado.

Da mesma forma que há critérios para a tradução dos nomes químicos para o português, os nomes usuais também devem seguir regras para evitar a sua desqualificação na língua portuguesa. Usualmente tais nomes ${ }^{2}$ (LENTINI, 2003) têm uma origem normalmente histórica envolvendo seus criadores, homenagens ou situações que remontam aos tempos da alquimia (LEIGH, 2012). Contudo, especificamente no caso de pesticidas, seus nomes usuais obedecem a uma regra simples: praticidade. A busca pela praticidade, no entanto, torna a estética uma propriedade secundária em termos de linguagem. Um exemplo é o pesticida 4-cloro-5(metilamino)-2-[3-(trifluorometil)fenil]piridazin-3-ona, exaustivamente citado na literatura em português brasileiro como norflurazon ou norflurazone, integralmente trazido do inglês que, pelas recomendações existentes em nomenclatura de compostos orgânicos em português brasileiro (DE ALENCASTRO, 1982; ABAKERLI et al., 2003), deveria ser grafado como norfluorazona, por apresentar o grupo cetona em sua estrutura química.

Tabela 1. Diversidade da nomenclatura sistemática e não sistemática para a norflurazona

\begin{tabular}{|c|c|}
\hline $\begin{array}{l}\text { Fórmula } \\
\text { Estrutural }\end{array}$ & \\
\hline Nome IUPAC (inglês) & $\begin{array}{l}\text { 4-chloro-5-(methylamino)-2-[3-(trifluoromethyl)phenyl]pyridazin-3- } \\
\text { one }\end{array}$ \\
\hline Nome IUPAC (português) & 4-cloro-5-(metilamino)-2-[3-(trifluorometil)fenil]piridazin-3-ona \\
\hline Nomes usuais (inglês) & $\begin{array}{l}\text { 4-chloro-5-(methylamino)-2-(alpha, alpha, alpha-trifluoro-m-tolyl)- } \\
3(2 \mathrm{H}) \text {-pyridazinone } \\
\text { norfluorazon } \\
\text { norflurazon } \\
\text { norflurazone } \\
\text { SAN } 9789\end{array}$ \\
\hline Outros Nomes & Outros 92 nomes de acordo com o PubChem ${ }^{3}$ \\
\hline
\end{tabular}

A Tabela 1 mostra a diversidade da nomenclatura de uma única substância, o que certamente provoca consequências desastrosas no momento da escolha do pesticida sem o auxílio técnico especializado, o que é frequente no Brasil.

\footnotetext{
2 http://www.sciencecompany.com/Glossary-of-Common-Chemical-Names.aspx

3 https://pubchem.ncbi.nlm.nih.gov/compound/norflurazon\#section=Depositor-Supplied-Synonyms
} 
Pinto e Alencastro (2010) publicam em um editorial da revista virtual de química sua preocupação com a falta de normatização nos idiomas portugueses (europeu e brasileiro), citando o impacto prejudicial em termos da impossibilidade de se ter um banco de dados de estruturas químicas no idioma português, o que afeta diretamente o setor industrial.

A nomenclatura sistemática criada pela IUPAC ${ }^{4}$, em inglês, é rica em lógica ao ponto de ser possível criar programas que traduzam a linguagem química (fórmulas estruturais) para a língua inglesa ${ }^{5}$. Contudo, a tradução desses softwares a fim de viabilizar a automatização da criação de nomes em português ainda é um desafio, as dificuldades são inúmeras e passam inclusive por questões de gênero e pela sintaxe (como o exemplo da norflurazona na Tabela 1).

\section{Metodologia empregada neste estudo}

Dado todo o exposto anteriormente, este projeto interdisciplinar visa, ao seu final, apresentar um glossário com termos harmonizados no par linguístico português inglês, com o objetivo de contribuir para a melhoria do cenário descrito.

Desta forma, para desenvolver este trabalho, foram selecionados textos da área de Química Orgânica junto ao grupo de pesquisa do Departamento de Química e Ciências Ambientais da UNESP. Os textos são provenientes de publicações científicas nas línguas portuguesa e inglesa e foram subdivididos em diferentes subcorpora, pois desta forma, o levantamento de termos em português e em inglês respeitará o gênero e a área científica envolvida.

Para esta investigação, foram compilados os seguintes corpora: 1) um corpus principal paralelo, composto por resumos da área de Química de Pesticidas, escritos originalmente em português e pelas respectivas traduções (abstracts) para o inglês; 2) um corpus de controle comparável composto por artigos na mesma área escritos originalmente em português; 3 ) um corpus de controle comparável composto por artigos escritos originalmente em inglês. Os artigos dos corpora paralelo e comparáveis foram retirados da revista Química Nova e de outras revistas relacionadas ao estudo, com edições mais recentes, cujos tópicos foram criteriosamente selecionados por alunos do curso de Química, sob orientação do docente responsável pela pesquisa neste departamento. Também foram utilizados dois corpora de referência para a extração de palavras-chave, ou seja, palavras estatisticamente relevantes para a área estudada. Em português, utilizamos o corpus Lácio-ref, composto por artigos em português em diferentes gêneros textuais, e para a extração de palavras-chave em inglês, empregamos o British National Corpus (BNC Sampler com 2.530.849 itens) composto por textos originalmente escritos em inglês.

Quanto aos procedimentos, os artigos escolhidos foram salvos em txt, a fim de serem processados pelo programa de análise lexical AntConc. No tocante às ferramentas disponibilizadas neste programa, foram utilizadas a WordList, KeyWord e Concordance.

\footnotetext{
${ }^{4} \mathrm{http}$ ://www.iupac.org/home/publications/e-resources/nomenclature-and-terminology.html

${ }^{5}$ http://www.acdlabs.com/resources/freeware/chemsketch/, http://web.chemdoodle.com/demos/iupacnaming, https://www.chemaxon.com/products/naming/, 
Como explica Berber Sardinha (2004), a ferramenta WordList gera uma lista de acordo com a frequência de cada palavra. Em seguida, utilizamos as listas fornecidas pela WordList para gerar uma lista de palavras-chave nas duas línguas. Este procedimento foi realizado com o aplicativo KeyWords. A seguir apresentamos um exemplo da tela com os termos em língua inglesa retirados do livro Pesticide Chemistry:

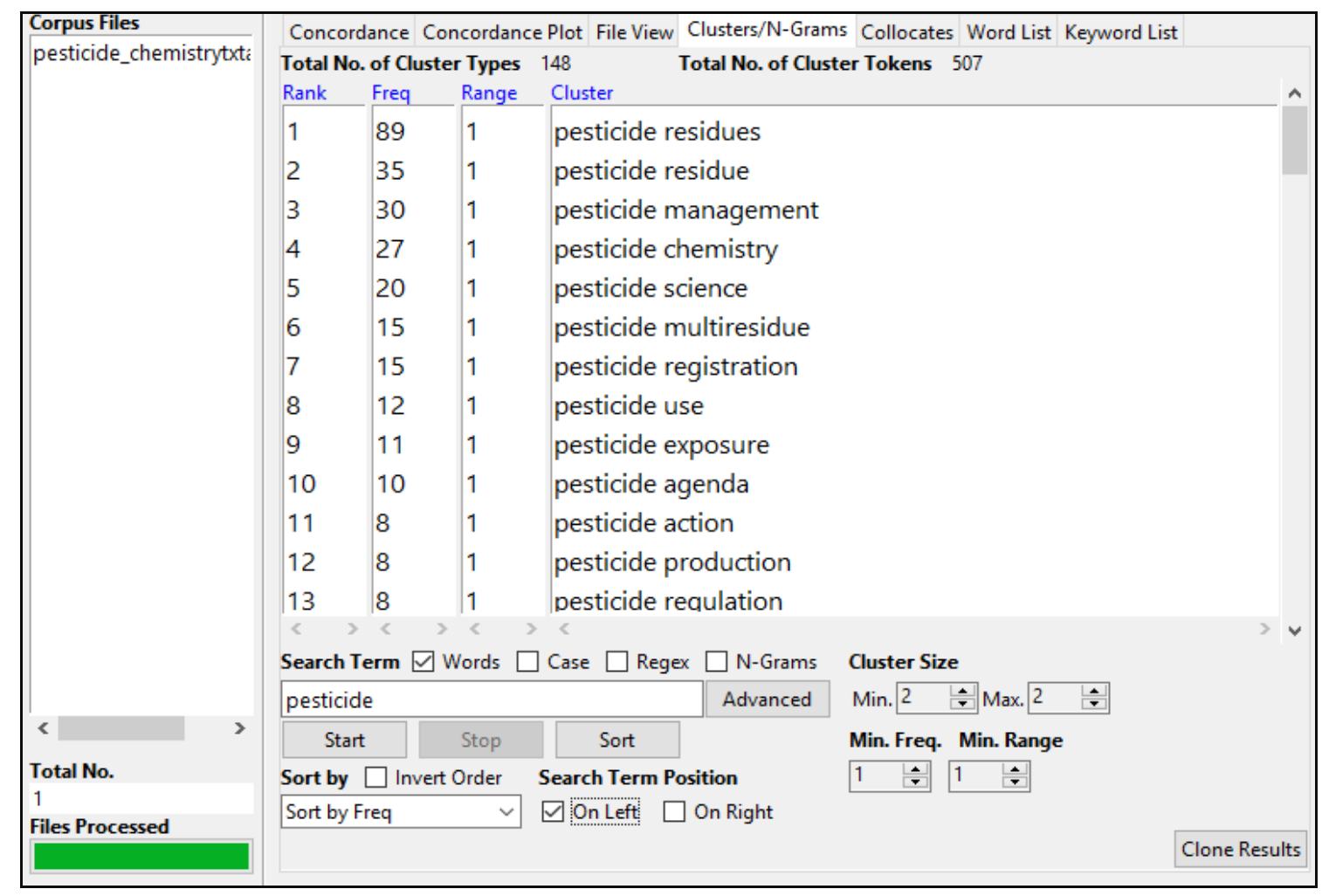

Figura 2. Levantamento de termos com o AntConc (SOUZA et al., no prelo)

Para a observação dos termos em contexto de uso, o aplicativo Concordance foi utilizado. Este aplicativo disponibiliza uma palavra de busca inserida em linhas que podem ser expandidas e analisadas. O levantamento de termos simples e compostos da área de Química de Pesticidas foi realizado, neste trabalho, com base nos substantivos mais frequentes.

\section{Dados parciais}

O projeto que está em andamento desde 2014 já levantou questões e apresentou dados importantes. Já realizamos o levantamento de palavras-chave em inglês e em português e, atualmente, estamos selecionando os equivalentes nas duas línguas a partir dos corpora compilados no estudo.

A seguir apresentamos algumas palavras-chave mais frequentes em inglês, presentes no livro Pesticide Chemistry, e os termos complexos observados a partir destas palavras: 
Tabela 2. Termos mais frequentes em língua inglesa extraídos do livro Pesticide Chemistry

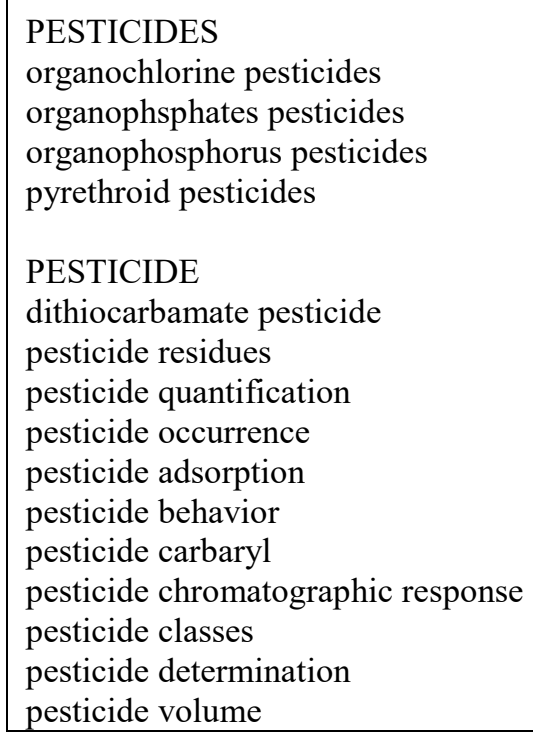

\section{DETERMINATION}

pesticides residue determination multiresidue determination pesticide-residue determination pesticide determination

\section{CHROMATOGRAPHY}

gas chromatography comprehensive two-dimension gas chromatography liquid chromatography high performance liquid chromatography] ultra performance liquid chromatographytandem mass spectrometry

Como podemos observar a partir do termo simples "pesticide", há uma lista ampla de termos complexos e compostos junto a esta palavra de busca. Após o levantamento de todos os termos extraídos do corpus em inglês, o grupo de pesquisadores da área de Tradução se reunirá com o grupo de Química, sejam estes alunos de graduação, pós ou docente, para que sejam selecionados os termos mais representativos da área para compor o glossário bilíngue. Além desta discussão, os termos em língua portuguesa também têm sido observados, uma vez que são retirados de revistas científicas conhecidas pela comunidade de pesquisadores de Química. No entanto, já pudemos obervar que a subárea da Química de Pesticidas ainda não apresenta muitos estudos no Brasil já que os termos constantes nos artigos em língua portuguesa acabam se misturando com outras subáreas da Química. Esta questão pode ser evidenciada nos termos mais frequentes apresentados na lista abaixo:

Tabela 3. Termos mais frequentes em língua portuguesa extraídos da Revista Química Nova

\begin{tabular}{|c|c|}
\hline $\begin{array}{l}\text { AGROTÓXICO } \\
\text { agrotóxicos organoclorados } \\
\text { agrotóxicos clorpirifós } \\
\text { resíduos de agrotóxicos } \\
\text { extração de agrotóxicos } \\
\text { análise de agrotóxicos } \\
\text { químicas dos agrotóxicos } \\
\text { aplicação de agrotóxicos } \\
\text { volatilização dos agrotóxicos } \\
\text { COMPOSTOS } \\
\text { extração de compostos } \\
\text { classe de compostos } \\
\text { retenção dos compostos } \\
\text { síntese de compostos } \\
\text { análise de compostos }\end{array}$ & $\begin{array}{l}\text { classes de compostos } \\
\text { quantificação dos compostos } \\
\text { químicas dos compostos } \\
\text { separação de compostos } \\
\text { série de compostos } \\
\text { cromatográfica dos compostos } \\
\text { decomposição dos compostos } \\
\text { degradação de compostos } \\
\text { deposição dos compostos } \\
\text { derivatização dos compostos } \\
\text { dissolução de compostos } \\
\text { lixiviação dos compostos } \\
\text { compostos orgânicos } \\
\text { compostos de nitrogênio } \\
\text { compostos voláteis } \\
\text { compostos químicos } \\
\text { compostos nitrogenados } \\
\text { compostos organoclorado }\end{array}$ \\
\hline
\end{tabular}


De acordo com os pesquisadores de Química, a revista Química Nova também traz artigos sobre Química Ambiental que discutem questões da Química Orgânica e Inorgânica, o que acaba gerando termos das duas subáreas que, por vezes, não fazem parte da Química de Pesticidas. A partir desta realidade, o grupo decidiu continuar a busca por equivalentes nos dois corpora, e também realizar uma pesquisa adicional em sites de órgãos que regulamentam a nomenclatura da Química para que possamos apresentar um glossário que realmente reflita os termos indicados pela literatura e aceitos pela comunidade científica.

\section{Considerações finais}

A investigação que vem sendo realizada entre o Departamento de Letras Modernas e o de Química e Ciências Ambientais da UNESP de uma universidade tem levantado questionamentos importantes e apontado para a necessidade de uma atuação conjunta para fins de harmonização de terminologia na subárea da Química de Pesticidas. É com o objetivo de auxiliar nesse aspecto que os pesquisadores trabalham juntos.

Foi verificado que o uso de ferramentas computacionais é de grande valia, pois facilita a análise de corpora eletrônicos por meio do processamento de grandes quantidades de informação. As linhas de concordância servem de apoio e esclarecem dúvidas em relação ao termo que se está levantando ao mostrar o contexto no qual ele se insere. No entanto, a intuição do analista, bem como as discussões com os profissionais da área são essenciais para o desenvolvimento de um trabalho como este.

Após o levantamento de termos de Química de Pesticidas, testaremos algumas plataformas on-line que facilitem o armazenamento dos termos para elaboração do glossário bilíngue da área, em que constem, além das recomendações para seus nomes usuais, seus respectivos sinônimos sistemáticos e não sistemáticos, para que sirva de referência para a academia e sociedade. Além disso, os alunos do curso de Tradução e de Letras de nossa instituição auxiliarão os alunos de Química na escrita de relatórios em língua inglesa e na tradução de artigos científicos que deverão ser traduzidos com o auxílio de memórias de tradução, para futuro reaproveitamento dos termos por outros alunos. Acreditamos que este estudo, ainda em andamento, possa fornecer subsídios a pesquisadores, tradutores e profissionais da área de Química no que concerne à tradução de textos para esta comunidade científica, além de favorecer um ambiente favorável à pesquisa interdisciplinar, o que consideramos um ponto de extrema relevância para o contexto universitário atual.

\section{REFERÊNCIAS}

ANDRADE, C. T.; COUTINHO, F. M. B.; DIAS, M. L.; LUCAS, E. F.; OLIVEIRA, C. M. F.; TABAK, D. Dicionário de polímeros. Rio de Janeiro: Editora Interciência, 2001.

AUBERT, F. H. Introdução à metodologia da pesquisa terminológica bilíngüe. São Paulo: Humanitas Publicações - FFLCH/USP, 1996. (Cadernos de terminologia 2). 
ABAKERLI, R. B.; FAY, E. F.; REMBISCHEVSKI, P.; VEKIC, A. M.; GODOY, K.; MAXIMIANO, A. A.; BONIFÁCIO, A. Regras para nomenclatura dos nomes comuns dos agrotóxicos. Pesticidas: Revista de Ecotoxicologia e Meio Ambiente, v. 13, p. 2936, jan./dez. 2003.

AZENHA JÚNIOR, J. Tradução técnica e condicionantes culturais: primeiros passos para um estudo integrado. São Paulo: Humanitas / FFLCH / USP, 1999.

BARROS, L. A. Curso básico de terminologia. São Paulo: USP, 2004.

BERBER SARDINHA, A. P. Lingüística de corpus: histórico e problemática. D.E.L.T.A., Documentação de Estudos em Linguística Teórica e Aplicada (PUC-SP. Impresso), São Paulo, EDUC, v. 16, n. 2, p. 323-367, 2000.

BERBER SARDINHA, A. P. Lingüística de Corpus. Barueri: Editora Manole, 2004.

COLlinS, C. H.; BRAGA, G. L.; BONATO, P. S. (Org.). Fundamentos de cromatografia. Campinas: Editora da UNICAMP, 2006.

DE ALENCASTRO, R. B. Nomenclatura dos compostos orgânicos. Química Nova, v. 5:3, p. 67-103, 1982.

DUBUC, R. Manuel pratique de terminologie. 2. ed. Québec: Linguatech, 1985.

KRIEGER, M. G.; FINATTO, M. J. B. Introdução à terminologia: teoria e prática. São Paulo: Contexto, 2004.

LEIGH, J. Systematic and trivial nomenclature. Chemistry International, v. 34, n. 5, p. 28-29, 2012.

LENTINI, G. Trivial, Common, and Systematic Chemical Names. Chemical Education Today, v. 80, n. 5, p. 487, 2003.

PINTO, A. C.; DE ALENCASTRO, R. B. Regras de nomenclatura química: como proceder? Revista Virtual de Química, v. 2, n. 4, p. 226, 2010.

SOUZA, J. V.; PINTO, P. T.; LIMA, M. F. A questão terminológica dos organofosforados na química de pesticidas: uma abordagem através da linguística de corpus, no prelo.

Recebido em: 10/10/2017

Aprovado em: 21/03/2018 